
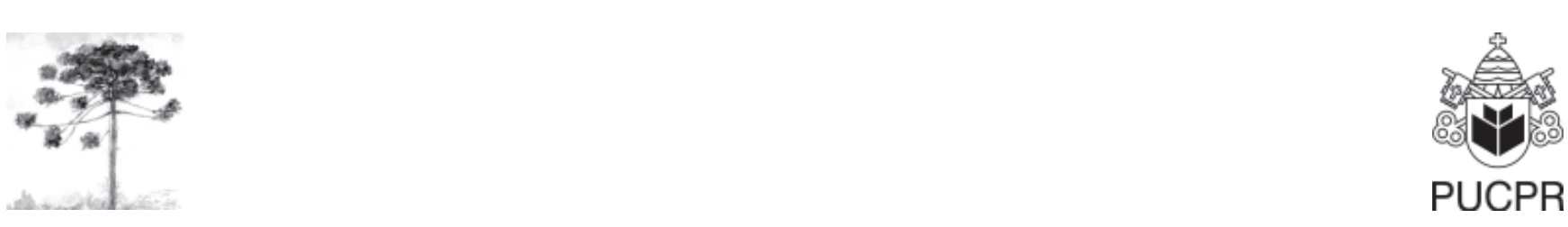

\title{
ESTUDO HISTOQUÍMICO DA MATRIZ EXTRACELULAR DE NEOPLASIAS TESTICULARES DE CÃES (Canis familiares Linnaeus, 1758)
}

\author{
Extracelular matrix histochemical study of testicular neoplasia in dogs \\ (Canis familiares Linnaeus, 1758)
}

\author{
Juliana Leone Staut ${ }^{[1]}$, Maria Laura Medeiros Assef ${ }^{[2]}$, Silvana Maris Cirio $^{[3]}$ \\ ${ }^{[1]}$ Bióloga pela Pontifícia Universidade Católica do Paraná (PUCPR), Mestre em Patologia pela Universidade Federal do \\ Paraná (UFPR), Curitiba, PR - Brasil, e-mail: leone@onda.com.br \\ ${ }^{[2]}$ Professora da Pontifícia Universidade Católica do Paraná (PUCPR), Curitiba, PR - Brasil, e-mail: laura.assef@pucpr.br \\ ${ }^{[3]}$ Professora Dra. da Pontifícia Universidade Católica do Paraná (PUCPR), Curitiba, PR - Brasil, e-mail: silvana.cirio@pucpr.br
}

\section{Resumo}

Cerca de $90 \%$ dos tumores testiculares acontecem em cães com idades entre oito e dez anos quando comparado aos demais animais domésticos. A criptorquidia, condição em que os testículos não descem da cavidade abdominal para a bolsa escrotal, é uma das principais causas, com incidência de 10 a 14 vezes maior de desenvolver neoplasias. Os tumores testiculares primários mais frequentes em cães são Seminoma, Sertolioma e Tumor de células intersticiais, também denominado de Leydigocitoma. A maioria desses tumores tem comportamento benigno, e a proporção de matriz extracelular é variável nesses processos neoplásicos. O objetivo do estudo foi caracterizar com o método de HE e Tricrômico de Picrosirius associado à polarização, o tipo de colágeno presente nas três neoplasias testiculares. Nas amostras analisadas, pode-se observar que há predomínio de colágeno tipo I que envolve de forma descontínua as massas neoplásicas, entretanto, por entre as células neoplásicas não ficou evidenciado nenhum tipo de colágeno.

Palavras-chave: Neoplasias testiculares; Criptorquidia; Aspectos histológicos. 


\begin{abstract}
Testicular tumors are very common in dogs at ages among eight and ten years old, because it represents more than $90 \%$ of all tumors in domestic dogs. The cryptorchidism, condition in which the testicles do not go from the abdominal cavity to the scrotum, is the main cause and the incidence is 10 to 14 times higher to develop neoplasias. The most frequent testicular primary tumors in dogs are Seminome, Sertoliome and Intersticial cell tumor, also called Leydigocitome. Most of them having benign behavior and large variability in quantities of extracellular matrix. The aim of this study was the characterization the collagen type in the testicular primary tumors in dogs using HE and Picrosirius technics in association with polarization. In the samples analyzed, there is collagen type I fibers disposed by discontinuous form around the neoplastic cells. However among the neoplastic cells was not shown any type of collagen. There is no colagenous fibers in the nests of neoplasic cells.
\end{abstract}

Keywords: Testicular neoplasias; Cryptorchid; Histological aspect.

\section{INTRODUÇÃO}

Entre os animais domésticos, as neoplasias testiculares são mais comuns em cães, chegando a $90 \%$ de incidência nessa espécie $(1,2)$. A criptorquidia, condição em que os testículos não descem da cavidade abdominal para a bolsa escrotal, favorece o desenvolvimento dessas neoplasias e o testículo retido tem de 10a14vezes maior probabilidade de desenvolver neoplasias em relação ao testículo da bolsa escrotal (3, 4). Em cães, os tumores testiculares primários mais comuns são Seminoma, Sertolioma (tumor de células de Sertoli) e Tumor de células intersticiais (de Leydig). A maioria tem comportamento benigno e geralmente não libera metástase $(2,5)$. Histologicamente, o tumor de células intersticiais e o Sertolioma são de origem gônado-estromal, enquanto o Seminoma origina de células germinativas. Essas três neoplasias podem ocorrersimultaneamente, emumou ambos os testículos, tanto como massas individuais, quanto associados uns aos outros. Além disso, existe variação visível na distribuição da matriz extracelular (MEC) quando do desenvolvimento das neoplasias (6).

A MEC é uma rede complexa de macromoléculas que proporciona um arcabouço físico para a estabilização da estrutura tecidual e modula o comportamento celular, não só em processos normais, mas também em processos neoplásicos. Seus principais componentes são as fibras colágenas, fibras elásticas, proteoglicanas e glicoproteínas com funções específicas. A associação de fatores específicos do hospedeiro, como resposta inflamatória, macromoléculas da MEC e neovascularização, com fatores relacionados à população de células neoplásicas, como a proliferação, invasão e expressão de marcadores celulares, resulta na expressão clínica e patológica da neoplasia (7-9).

As técnicas histoquímicas podem ser de grande valia para estudar proteínas fibrilares da matriz extracelular, e sua aplicação ajuda a caracterizar e diferenciar as neoplasias. O método de coloração por Tricrômico de Picrosírius consiste na coloração em vermelho pelo Sirius Red da proteína colágeno presente nas fibras colágenas, reticulares, cartilagens e nas membranas basais. Quando associada à microscopia de polarização, possibilita a visualização de colágeno pela organização paralela das moléculas de tropocolágeno. As fibras de colágeno tipo I apresentam coloração que varia do vermelho ao amarelo brilhante com intensa birrefringência. O colágeno tipo II apresenta birrefringência menos intensa e coloração amarelo pálida. O colágeno tipo III aparece como fibras delicadas de coloração esverdeada $(9,10)$.

A inter-relação entre as células do estroma com os elementos da MEC apresenta profunda implicação na biologia das neoplasias e pode parcialmente explicar os períodos de latência na carcinogênese e estabelecimento de metástases, além de proporcionar maior entendimento da fisiologia e consequente terapia do processo neoplásico (6).

O objetivo do presente trabalho foi caracterizar com utilização do método Tricrômico de Picrosirius associado à polarização, o tipo de 
colágeno presente nas três neoplasias primárias de testículo de cão (Canis familiares Linnaeus, 1758), como ponto de partida para a interpretação da matriz extracelular nessas neoplasias.

\section{MATERIAL E MÉTODOS}

As amostras de Seminoma, de Sertolioma e Tumor de células intersticiais diagnosticados em testículos de cães foram provenientes da rotina do Laboratório de Patologia Veterinária do câmpus São José dos Pinhais da PUCPR. Seguindo a metodologia para microscopia de luz, fragmentos de tecido neoplásico foram fixados em solução de formol $10 \%$ por 24 horas, desidratados em concentrações crescentes de álcool etílico por uma hora em cada, a partir de álcool $70 \%$ até o absoluto. A diafanização foi realizada em xilol e a infiltração e emblocagem em parafina histológica a $58^{\circ} \mathrm{C}(11,12)$. Cortes de 4ìm foram corados com Hematoxilina-Eosina (12) e Tricrômico de Picrosírius-Hematoxilina segundo protocolo do Laboratório de Patologia Experimental da PUCPR, onde as lâminas selecionadas foram fotografadas no equipamento Olympus BX50, com o auxílio do software Image Pro-Plus.

\section{RESULTADOS E DISCUSSÃO}

Nas amostras de Seminoma observou-se densa proliferação de células neoplásicas infiltradas entre os túbulos seminíferos. Havia atrofia tubular adjacente à massa neoplásica. As células eram uniformes, citoplasma claro e os núcleos com aspecto vesicular, com nucléolos proeminentes (Figura 1), de acordo com a descrição de Montenegro (13) e Nielsen e Lein (1). Sob polarização, a túnica albugínea, assim como as trabéculas conjuntivas que se projetavam por entre as células neoplásicas da periferia da massa, apresentavam coloração que variou do vermelho ao amarelo, comintensa birrefringência sugerindo serem colágeno do tipo I. Na porção central da neoplasia, as fibras colágenas não eram visíveis (Figura 2).

OTumor de células intersticiais apresentava o aspecto nodular esferoide característico, sendo compatível com os relatos de Nielsen e Lein (1) e
Buergelt (6). Suas células eram pálidas pela presença de vacúolos intracitoplasmáticos, e os núcleos esféricos e hipercromáticos (Figura 3). A vascularização estava presente no nódulo, mas não era evidente, ao contrário do que relatam Nielsen e Lein (1). Além da albugínea rica em colágeno tipo I, a polarização evidenciou fina rede de fibras semelhantes ao redor dos túbulos seminíferos, sugerindo a presença também de colágeno tipo I. Por entre as células neoplásicas a polarização não evidenciou matriz, apenas o delicado contorno de tecido conjuntivo ao redor do nódulo neoplásico, corroborando com os achados de Nielsen e Lein (1) (Figura 4).

As amostras de testículos comprometidos pelo desenvolvimento do Sertolioma mostraram densa população de células com aparência espumosa pela grande quantidade de vacúolos lipídicos intracitoplasmáticos. Os limites celulares estavam indefinidos, e por essa razão os núcleos pareciam estar num citoplasma fibrilar, aspecto compatível com aquele descrito por Nielsen e Lein (1). Esta neoplasia apresentou padrões variáveis de concentração celular, assim como de vacúolos intracitoplasmáticos, como relatado por Nielsen e Lein (1), Mazzanti et al. (5) Buergelt (6), Montenegro (13) e Silva (14) (Figura 5). Chamou a atenção que nas áreas com predomínio de células neoplásicas vacuolizadas, o tecido conjuntivo era mais abundante, formando trabéculas irregulares de colágeno I, evidenciadas pela polarização. Nas regiões onde as células formavam densas populações, as trabéculas não eram visíveis (Figuras 6).

O método Tricrômico de Picrosirius simples e associado à polarização permitiu identificar colágeno I na túnica albugínea. Este tipo de colágeno é encontrado predominantemente na cápsula dos órgãos, como descreve Junqueira (10). O mesmo tipo de colágeno está circundando de forma descontínua os agrupamentos de células neoplásicas. No interior desses aglomerados, a polarização não evidenciou fibras colágenas. Martins et al. (9) descreveram a presença de fibras reticulares e elásticas, entremeadas a células neoplásicas de carcinomas mamários, cuja visualização foi possível com técnicas histoquímicas específicas. 


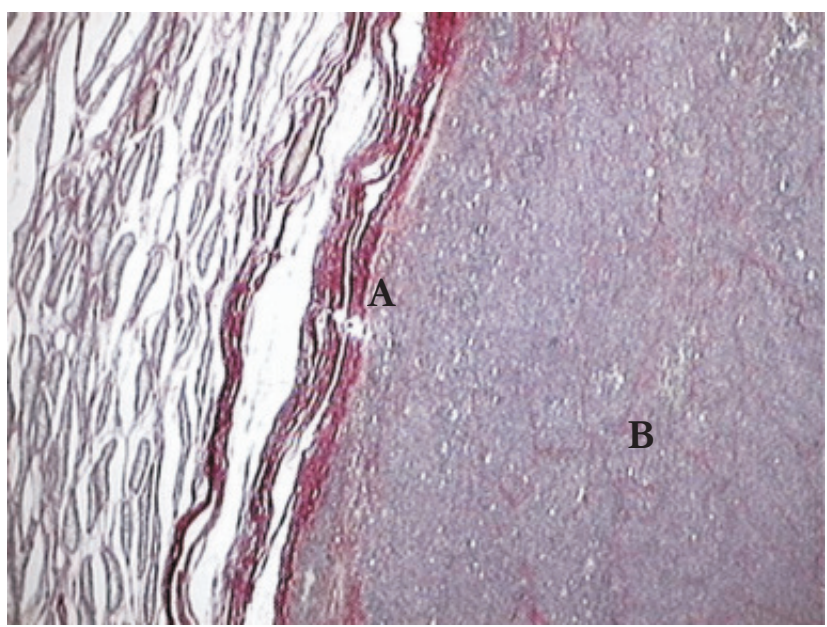

FIGURA 1 - Testículo. Cão. Seminoma. (A) Albugínea. (B) Células neoplásicas comprimindo túbulos adjacentes. Tricrômico de Picrosirius. 40X

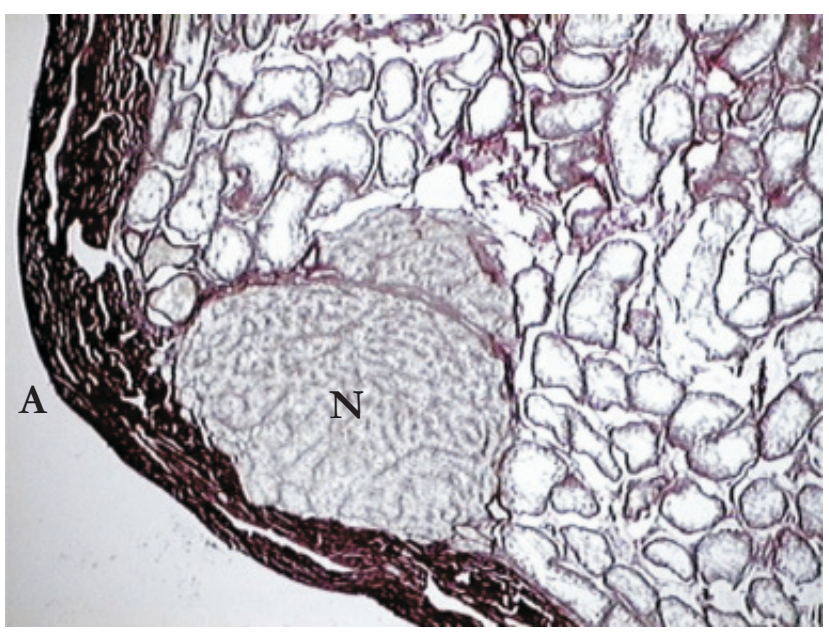

FIGURA 3 - Testículo. Cão. Tumor de células intersticiais. (A) Albugínea. (N) Aspecto nodular.'Tricrômico de Picrosirius. 40X

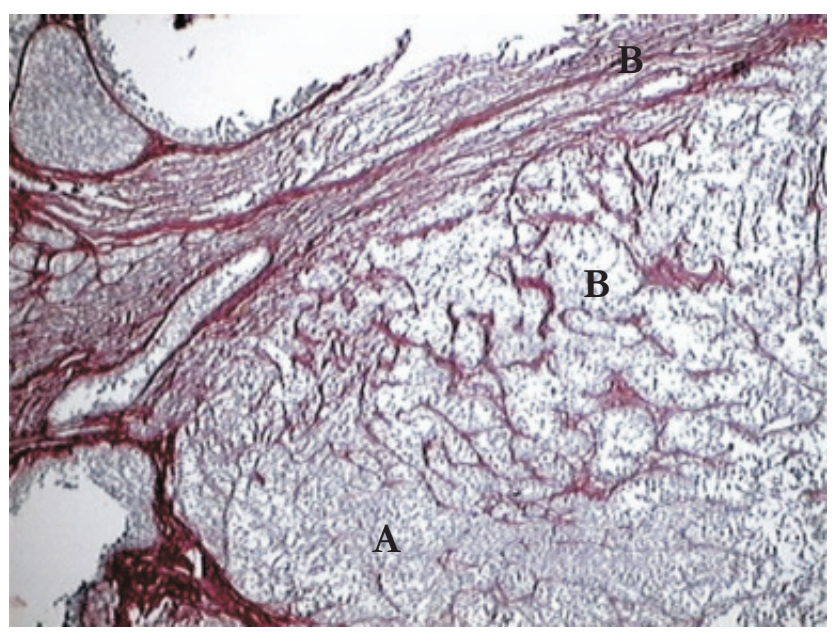

FIGURA 5 - Testículo. Cão. Sertolioma. (A) Região densamente celularizada. (B) Região com células vacuolizadas. Tricrômico de Picrosírius. 40X.

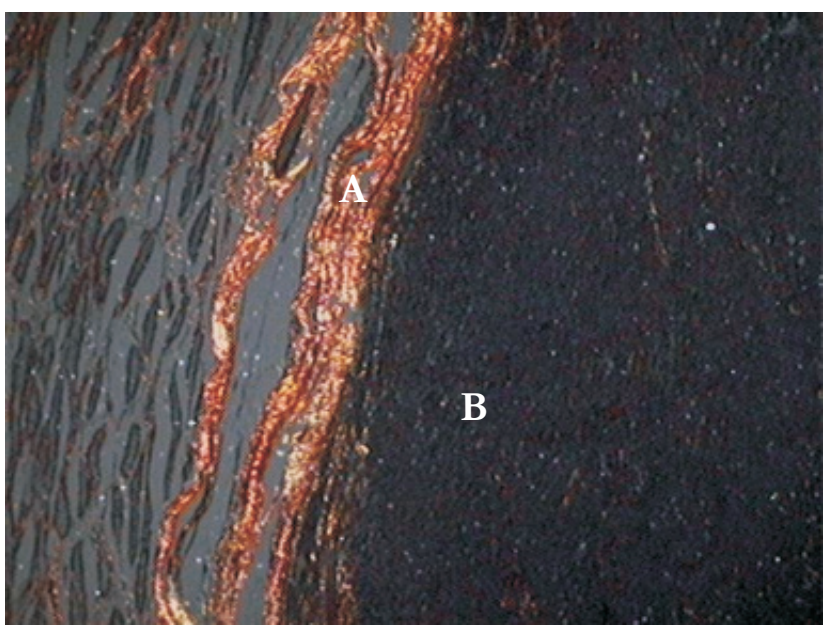

FIGURA 2 - Testículo. Cão. Seminoma. (A) Albugínea. Colágeno tipo I(B) Células neoplásicas. Tricrômico de Picrosirius sob polarização). 40X

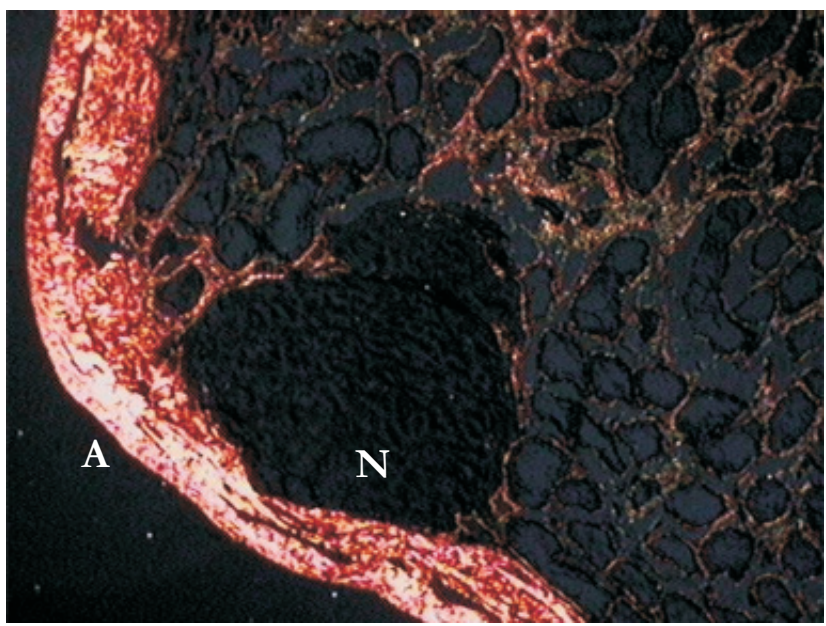

FIGURA 4 - Testículo. Cão. Tumor de células intersticiais. (A) Albugínea com fibras colágenas tipo I, (N) Nódulo neoplásico. Tricrômico de Picrosirius sob polarização). $40 \mathrm{X}$

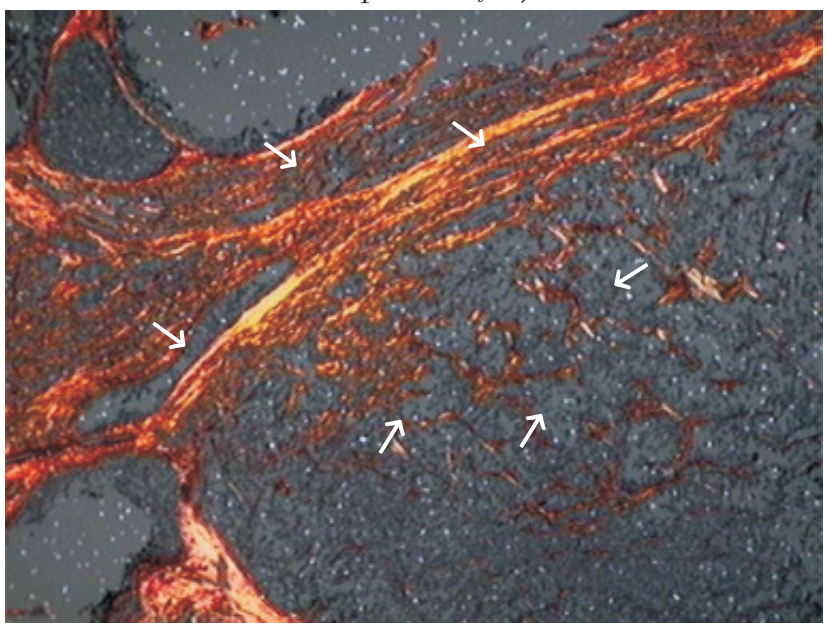

FIGURA 6 - Testículo. Cão. Sertolioma. Fibras colágenas do tipo I (setas), entre as células de Sertoli vacuolizadas evidenciadas pelo Tricrômico de Picrosírius sob polarização. 40X 


\section{CONCLUSÃO}

Por causa da complexidade e variáveis histológicas das neoplasias, os resultados obtidos incentivam a novos estudos com técnicas histoquímicas para melhor caracterização dos elementos da matriz extracelular de neoplasias testiculares de cães.

\section{REFERÊNCIAS}

1. Nielsen SW, Lein DH. VI. Tumours of the testis. Bull World Health Organ. 1974;50 (1):71-78.

2. Santos CM, Silva AFC. Ribeiro R, Serakides RL. Testicular tumors in dogs: frequency and age distribution. Arq Bras Med Vet Zootec. 2000;52(1):25-26.

3. Jubb KVF, Kennedy PC, Palmer N. Pathology of domestic animals. San Diego: Academic Press; 1993.

4. Staut JL, Henz GM, Telles JEQ, Cirio SM. Análise da expressão da proteína p53 anômala em uma série de neoplasias testiculares caninas. Anais do $52^{\circ}$ Congresso Brasileiro de Genética; Foz do Iguaçu, Congresso Brasileiro de Genética; 2006. p. 16.

5. Mazzanti A, Raiser AG, Pippi NL, Stigger AL, Sanches AWD, Leotte AM. Sertolioma em cão associado a criptorquidia bilateral e torção testicular. São Paulo: Redevet; 2001.

6. Buergelt CD. Color atlas of reproductive pathology of domestic animals. St. Louis: Mosby; 1997.

7. Alberts B, Johnson A, Lewis J, Raff M, Roberts K, Walter P. Biologia molecular da célula. 4a ed. Porto Alegre: Artmed; 2004.

8. Junqueira LC, Carneiro J. Histologia básica. $10 \mathrm{a}$ ed. Rio de Janeiro: Guanabara Koogan; 2004.

9. Martins AMCRPF, Tamaso E, Guerra JL. Histochemical study of fibrilar proteins of the extracellular matrix in benign and malignant mammary neoplasms in dogs. Braz J Vet Res Anim Sci. 2002;39(1):43-9.

10. Junqueira LC, Bignolas G, Brentani RR. Picrosirius staining plus polarization microscopy, a specific method for collagen detection in tissue sections. Histochemical Journal. 1979;11(4):447-55.

11. Beçak W, Paulete J. Técnicas de citologia e histologia. Rio de Janeiro: Ao Livro Técnico; 1976.

12. Tolosa EM, Rodrigues CJ, Behmer AO, Freitas Neto AG. Manual de técnicas para Histologia normal e patológica. 2a ed. São Paulo: Manole; 2003.

13. Montenegro MR, Franco M. Patologia: processos gerais. 4a ed. São Paulo: Atheneu; 2004.

14. Silva JF. Sertolinoma maligno em testículo ectópico de gato (Felis catus). Revista Por Ciên Vet. 2002;97(542):87-92.

Recebido: 18/07/2007

Received: 07/18/2007

Aprovado: 14/10/2007

Approved: 10/14/2007 